\title{
Effects of crop and weed densities on the interactions between barley and Lolium rigidum in several Mediterranean locations
}

\author{
Jordi IZQUIERDO ${ }^{a *}$, Jordi RECASENS ${ }^{\mathrm{b}}$, César FERNÁNDEZ-QuINTANILLA ${ }^{\mathrm{c}}$, Gurjeet GILL ${ }^{\mathrm{d}}$ \\ ${ }^{\text {a }}$ Dept. d'Enginyeria Agroalimentària i Biotecnologia, Universitat Politècnica de Catalunya, C/ Comptes d'Urgell, 187, 08036 Barcelona, Spain \\ ${ }^{\mathrm{b}}$ Dept. de Hortofructicultura, Botànica i Jardineria, Universitat de Lleida, Av. Rovira Roure 177, 25198 Lleida, Spain \\ ${ }^{c}$ CCMA-CSIC, Serrano, 115 B, 28006 Madrid, Spain \\ d Dept. of Agronomy and Farming Systems, Roseworthy Campus, University of Adelaide, 5371 Roseworthy, SA, Australia
}

(Received 8 July 2002; accepted 29 November 2002)

\begin{abstract}
The effects of both barley and Lolium rigidum densities on weed growth and spike production and on crop yield were examined in five field experiments carried out in the Mediterranean drylands of Spain and Western Australia. The aim was to check the consistency of the competitiveness of the crop in different environmental and management conditions. L. rigidum reduced barley yields in most of the experiments (between 0 and $85 \%$ ), the number of ears per $\mathrm{m}^{2}$ being the most affected. It was found that increasing the barley seeding rate did not reduce the crop losses but did limit weed biomass (between 5 and 61\%) and spike production (between 24 and 85\%). The variability observed in crop yield losses between sites and seasons was related to rainfall at the beginning of the season. The most sensitive component of yield to weed competition was the number of ears per plant.
\end{abstract}

interference / barley / Lolium rigidum / crop yield / Mediterranean region

Résumé - Effets des densités de la culture et des adventices sur les interactions entre l'orge et Lolium rigidum dans plusieurs sites méditerranéens. Les effets combinés des densités de l'orge et de Lolium rigidum sur la croissance des adventices et la production d'épis et sur le rendement cultural ont été examinés dans cinq parcelles expérimentales mises en place dans les terres arides méditerranéennes d'Espagne et de l'Ouest de l'Australie. L'objectif était de vérifier l'importance de la compétitivité de la culture dans différentes conditions environnementales et culturales. L. rigidum a réduit les rendements en orge dans la majorité des expérimentations (entre 0 et $85 \%$ ), le nombre d'épi au $\mathrm{m}^{2}$ ayant été le plus affecté. Il a été montré qu'en augmentant la densité de semis d'orge, on ne réduisait pas les pertes de rendement mais on limitait la biomasse d'adventices (entre 5 et $61 \%$ ) et la production d'épis (entre 24 et $85 \%$ ). La variabilité observée au niveau des pertes de rendement de la culture entre les sites et les saisons a été reliée aux précipitations du début de la saison. La composante du rendement la plus sensible à la compétition avec les adventices a été le nombre d'épis par plante.

interférence / orge / Lolium rigidum / rendement / région méditerranéenne

\section{INTRODUCTION}

Annual ryegrass (Lolium rigidum Gaudin) is one of the most widespread weeds in the Spanish drylands. According to several surveys, Lolium sp have been found in more than 800000 ha of cereal fields in Spain [9]. L. rigidum was present in more than $50 \%$ of the cereal fields of Catalonia [25], 24\% in the Duero Valley [9] and 35\% in Andalucia [28], being considered as the most abundant grass weed in the cereal fields of Catalonia and the Duero Valley. Several studies indicate that $L$. rigidum can be an extremely competitive weed in cereal crops $[6,17,26]$. Various ecological characters of L. rigidum appear to have contributed to the success of this species as a weed of agriculture. Its high genetic variability [12], high seed production [7] and high seed survival over summer and autumn [14] facilitate the long-term survival of this weed.

Mediterranean climate areas are characterised by their high climatic variability. Long drought periods are relatively common during the growing season, limiting the number of alternative crops and influencing competitive effects of weeds. Herbicides are the main method for the control of L. rigidum, but several facts threaten the sustainability of this strategy. The variability of the Mediterranean climate often causes erratic herbicide efficacy. In addition, herbicide resistance in L. rigidum populations to several herbicide groups have been increasingly reported in the last decade [2, 10, 15, 21, 24].

Communicated by Gérard Guyot (Avignon, France)

* Corresponding author: jordi.izquierdo@upc.es 
Table I. Details of the experiments.

\begin{tabular}{|c|c|c|c|c|c|c|c|c|c|}
\hline Experiment $^{(1)}$ & Season & $\begin{array}{l}\text { Rainfall }_{(\mathrm{(2)}} \\
(\mathrm{mm})\end{array}$ & Sowing date & Harvest date & $\begin{array}{l}\text { Plot size } \\
(\mathrm{m} \times \mathrm{m})\end{array}$ & $\begin{array}{l}\text { Experimental } \\
\text { units }\end{array}$ & $\begin{array}{c}\text { Barley sowing rate } \\
\left(\mathrm{kg} \cdot \mathrm{ha}^{-1}\right)\end{array}$ & $\begin{array}{c}\text { Barley density }{ }^{(3)} \\
\left(\text { plants } \cdot \mathrm{m}^{-2}\right)\end{array}$ & $\begin{array}{l}\text { L. rigidum density }{ }^{(4)} \\
\quad\left(\text { plants } \cdot \mathrm{m}^{-2}\right)\end{array}$ \\
\hline$\overline{\text { ALG94L }}$ & $93 / 94$ & 99 (12) & $12 \mathrm{Nov}$ & 27 May & $1.5 \times 8.5$ & 20 & 75 & 210 & $0-620$ \\
\hline ALG94M & & & & & & 20 & 150 & 376 & $0-622$ \\
\hline ALG94H & & & & & & 20 & 300 & 663 & $0-502$ \\
\hline ALG95L & $94 / 95$ & $87(42)$ & $3 \mathrm{Nov}$ & 30 May & $1.5 \times 8.5$ & 20 & 75 & 294 & 0-1011 \\
\hline ALG95M & & & & & & 20 & 150 & 621 & $0-968$ \\
\hline ARG95L & $94 / 95$ & $175(73)$ & 16 Nov & 6 June & $1.5 \times 8.5$ & 20 & 60 & 196 & $0-2485$ \\
\hline ARG95M & & & & & & 20 & 120 & 262 & $0-2187$ \\
\hline WH96L & 95 & $231(148)$ & 16 June & $29 \mathrm{Nov}$ & $1.5 \times 25$ & 12 & 25 & 65 & $0-572$ \\
\hline WH96M & & & & & & 12 & 50 & 109 & $0-396$ \\
\hline WH96H & & & & & & 12 & 200 & 268 & $0-309$ \\
\hline GUI00 & $99 / 00$ & $227(94)$ & 16 Oct & 8 June & $2 \times 5$ & 50 & 150 & 336 & $0-4558$ \\
\hline
\end{tabular}

(1) ALG, Alguaire; ARG, Arganda; GUI, Guissona; WH, Wongan Hills; L, low density; M, medium density; H, high density.

(2) Rainfall in the first two months after sowing in brackets.

(3) Average densities measured at crop maturity.

(4) Range of achieved densities measured at crop maturity.

Adoption of other strategies leading to an increase in the competitive ability of the crop could be a feasible way to suppress L. rigidum populations. Lemerle et al. [18] have shown that the genetic variability present in Australian wheat varieties can be used to increase competitiveness of the crop. Alternatively, manipulating crop agronomy, such as increasing the crop seeding rate $[20,29]$, may be a practical alternative.

Barley, one of the most important crops in the Mediterranean areas, is generally considered to be very competitive against $L$. rigidum $[4,8,22]$. In spite of that, yield losses caused by this weed are frequently serious in commercial crops. Although there is considerable information on the competitive effect of $L$. rigidum on wheat, this information cannot be extrapolated to barley because of large differences between the two crop species in competitive ability with weeds. Lemerle et al. [16] reported similar competitiveness of the two crops against $L$. rigidum, but the observed responses depended strongly on the crop cultivar and season.

Few studies have focused on the geographical consistency of this crop/weed interaction process. If advice is to be generated for farmers on how to achieve a competitive crop, the likely variability in crop/weed response to increasing crop density should be known. According to Goldberg [13], a competitive crop can be defined either as one that maintains a stable yield in the presence of other plants (tolerant of competition), or as one that is able to reduce plant growth effectively (able to suppress competitors). The work reported here addressed both aspects, studying the density dependence of the biomass and spike production of L. rigidum and the yield losses of barley. Five field experiments were conducted in distinct Mediterranean sites in order to check the consistency of the competitiveness of the crop in different environmental and management conditions.

\section{MATERIALS AND METHODS}

\subsection{Site description}

Field experiments were conducted in four commercial barley fields in Mediterranean climate areas of Spain and Australia.
Experiments were carried out in Alguaire (Catalunya) in 93/94 (ALG94) and 94/95 (ALG95), Arganda (Central Spain) in 94/ 95 (ARG94/95), Wongan Hills (Western Australia) in 1996 (WH96) and Guissona (Catalunya) in 99/00 (GUI00). The sites presented no previous history of L. rigidum presence. Soil textures were loamy in Alguaire and Arganda, sandy loam in Wongan Hills and silty loam in Guissona. Several years prior to the start of these experiments, the fields were sown with barley in Spain and a wheat-lupin rotation in Australia.

\subsection{Experimental design}

Barley varieties were selected by the site managers according to their local conditions. The 6-row cultivar Dobla was sown in Alguaire and Arganda and the 2-row cultivar Hispanic was used in Guissona. The 2-row cultivar Yagan was sown in Wongan Hills. All cultivars had an average height of (90$100 \mathrm{~cm}$ ), quick growth and were suited to late sowing in low rainfall areas.

A split-plot design was used in Alguaire and Arganda, with barley density in the main plots and L. rigidum density in the subplots. Details of the experiments are given in Table I. In Alguaire there were three barley sowing rates in the first season, but in the next one the highest seeding rate was eliminated because the high number of barley plants $\left(663 \mathrm{pl} \cdot \mathrm{m}^{-2}\right)$ that emerged in the plots caused a high intraspecific crop competition that masked the crop/weed interaction. In the second season the number of replicates was increased from three to four as a consequence of the high yield variability observed between plots with the same plant densities. The homogeneity of the field in Wongan Hills allowed the use of a randomised block design with three replicates. Data from the $100 \mathrm{~kg} \cdot \mathrm{ha}^{-1}$ crop seeding rate plots was discarded in this site due to technical problems associated with seeding this treatment. In these sites barley was sown with a plot-seeding machine and L. rigidum was hand-broadcast later onto the plots the same day; each plot was then raked to incorporate the seeds of L. rigidum.

Weed seeds in Alguaire and Arganda were obtained from natural populations and from a commercial supplier in Wongan Hills. Five weed seeding weights were sown in the Spanish sites 
and three in Australia. These seeding weights gave a wide range of seedling densities in the plots (Tab. I). In ALG95 L. rigidum seeding weights were increased in the second season in order to observe better the competitive effect on the crop.

In Guissona the experiment was carried out in a commercial field of barley with naturally occurring populations of L. rigidum. Barley was sown with a commercial seed drill and the patchy distribution of $L$. rigidum gave a wide range of weed densities. Plots were marked out on a regular $10 \mathrm{~m} \times$ $15 \mathrm{~m}$ grid after crop and weed emergence.

\subsection{Husbandry}

Fertiliser was hand-broadcast onto each plot at sowing, except in Guissona. Applications were $300 \mathrm{~kg} \cdot \mathrm{ha}^{-1}$ of $10 \mathrm{~N}: 20 \mathrm{P}: 20 \mathrm{~K}$ in the experiments conducted in Alguaire and $500 \mathrm{~kg}$ of $8 \mathrm{~N}: 24 \mathrm{P}: 8 \mathrm{~K}$ in Arganda. In Wongan Hills, applications were $58 \mathrm{~kg} \cdot \mathrm{ha}^{-1}$ of diammonium phosphate $(18 \%$ $\left.\mathrm{N} ; 46 \% \mathrm{P}_{2} \mathrm{O}_{5}\right)$ and $50 \mathrm{~kg} \cdot \mathrm{ha}^{-1}$ of urea $(46 \% \mathrm{~N})$. In Guissona, the farmer spread $300 \mathrm{~kg} \cdot \mathrm{ha}^{-1}$ of manure pre-sowing, which is comparable with that of the other sites. A second application was carried out in Alguaire and Arganda by the end of winter with $200 \mathrm{~kg} \cdot \mathrm{ha}^{-1}$ of ammonium nitrosulphate $(26 \% \mathrm{~N})$. At these sites, broad-leaved weeds were controlled by $0.8 \mathrm{~L} \cdot \mathrm{ha}^{-1}$ of 2,4-D (Esteron 60, $600 \mathrm{~g}$ a.i. $\mathrm{L}^{-1}$, Dow AgroSciences) at the beginning of the spring and grass weeds such as Avena sp. and Bromus sp. were pulled out by hand. In Wongan Hills, glyphosate (Roundup Plus, $360 \mathrm{~g}$ a.i. $\cdot \mathrm{L}^{-1}$, Aventis CropScience Ltd.) was sprayed at $4 \mathrm{~L} \cdot \mathrm{ha}^{-1}$ for pre-sowing weed control. No herbicide was sprayed in Guissona due to the absence of weeds other than L. rigidum.

\subsection{Measurements}

Actual crop and weed densities were determined at crop maturity. No significant mortality of plants was observed during the seasons. Sampling was carried out in all experiments using two quadrats of $50 \mathrm{~cm} \times 50 \mathrm{~cm}$ per plot, which represented a total sampled area of $0.5 \mathrm{~m}^{-2}$. Weed and crop plants within the quadrats were removed from the soil, counted, cut off at the roots and stored in bags for further processing. Weed biomass in all experiments was assessed by drying the plants at $80{ }^{\circ} \mathrm{C}$ for 36 hours. The number of spikes of L. rigidum was counted in ALG94 and WH96. Barley grain yield and yield components were determined from all the samples. The number of grains per ear and the 1000 grain weight were estimated from 20 ears selected at random from each sample.

\subsection{Regression analyses}

Analysis was done on the pooled data from the two quadrats. Considering the limited range of barley densities of the experiments, the effect of the crop on the weed was evaluated by analysing the relationship between $L$. rigidum biomass or number of spikes and L. rigidum plant density for each sowing density of barley separately. The model selected to fit the data was the rectangular hyperbolic equation proposed by Cousens [3]:

$$
y=i d /(1+(i d / a))
$$

where $y$ is the biomass in $\mathrm{g} \cdot \mathrm{m}^{-2}$ or spikes $\cdot \mathrm{m}^{-2}$ of $L$. rigidum, $d$ is the weed density in plants $\cdot \mathrm{m}^{-2}, i$ is the weed biomass or the number of spikes per unit weed density as $d$ approaches zero and $a$ is the maximum weed biomass or number of spikes at infinite weed density.

The effect of the weed on the crop was evaluated by analysing the relationship between weed density and barley yield/yield components separately for each sowing density, using the rectangular hyperbola described by Cousens [3]:

$$
y=Y_{w f}(1-\{i d /[1+(i d / a)]\})
$$

where $y$ is the yield of barley or any of its components, $Y_{w f}$ is the weed-free yield, $i$ is the yield or yield component as weed density approaches zero, $a$ is the maximum yield or yield component at infinite weed density and $d$ is the weed density in plants $\cdot \mathrm{m}^{-2}$.

The goodness-of-fit of the data to the model was identified from the standard errors of the parameters $i$ and $a$, the proportion of the variation in the data accounted for by the model (Adj $\mathrm{R}^{2}$ ) and by graphical analysis of the residuals. Analyses were done using the SAS software package (SAS Institute Inc., Cary, NC, USA).

As weak competition was observed in some sites and years, we tried to determine if there was any effect of the rainfall on the measured variables. Pearson correlations (r) were made between rainfall collected throughout the growing season, and during the first two months after sowing, with the parameters of the fitted models.

\section{RESULTS}

\subsection{Effect of barley density and weed density on $L$. rigidum biomass}

The relationships between weed density and weed biomass were hyperbolic in shape in all cases (Fig. 1), with $\mathrm{R}^{2}$ being 0.68 or higher (Tab. II), indicating that L. rigidum biomass was dependent on both crop and weed density. Low crop densities allowed individual weed plants to become larger, but the high intraspecific competition which occurred at high L. rigidum densities caused this relationship to reach a plateau. The difference in maximum biomass achieved by the weeds, given by the parameter $a$ of the model, between the highest and lowest crop density was significant $(P<0.01)$ in all the experiments except ARG95. The difference was 5\% in ARG95, 29\% in ALG95, 49\% in ALG94 and 61\% in WH96. The non-significant $5 \%$ reduction in weed biomass with increasing crop density in ARG95 was probably due to the fact that the barley densities achieved in the two treatments $\left(196 \mathrm{pl} \cdot \mathrm{m}^{-2}\right.$ on average for the low density and 262 for the medium density) were fairly similar.

The biomass of the weed differed greatly between sites and years. According to the $a$ parameter of the models fitted (Tab. II), the maximum biomass estimated in ALG94 ranged between 211 and $277 \mathrm{~g} \cdot \mathrm{m}^{-2}$ for the medium and low barley densities, respectively. The following year (ALG95), maximum biomass ranged between 346 and $489 \mathrm{~g} \cdot \mathrm{m}^{-2}$, probably 

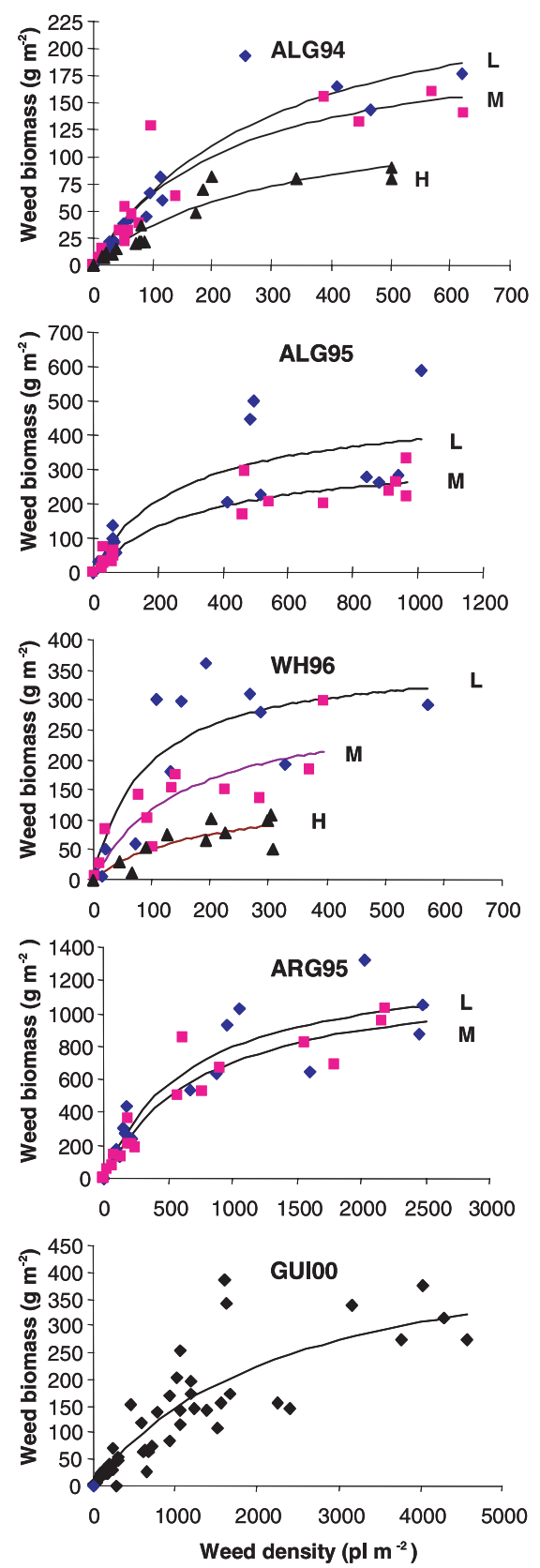

Figure 1. Relationships between the biomass $\left(\mathrm{g} \cdot \mathrm{m}^{-2}\right)$ and the density (plants $\cdot \mathrm{m}^{-2}$ ) of L. rigidum at the different barley densities. Response curves are those from the parameters given in Table II.

ALG94: Alguaire 1993/94. Barley densities: L $75 \mathrm{~kg} \cdot \mathrm{ha}^{-1}$; M $150 \mathrm{~kg} \cdot \mathrm{ha}^{-1} ; \mathrm{H} 300 \mathrm{~kg} \cdot \mathrm{ha}^{-1}$

ALG95: Alguaire 1994/95. Barley densities: L $75 \mathrm{~kg} \cdot \mathrm{ha}^{-1}$; M $150 \mathrm{~kg} \cdot \mathrm{ha}^{-1}$.

WH96: Wongan Hills 1995. Barley densities: L $25 \mathrm{~kg} \cdot \mathrm{ha}^{-1}$; M $50 \mathrm{~kg} \cdot \mathrm{ha}^{-1} ; \mathrm{H} 200 \mathrm{~kg} \cdot \mathrm{ha}^{-1}$.

ARG95: Arganda 1994/95. Barley densities: L $60 \mathrm{~kg} \cdot \mathrm{ha}^{-1}$. M $120 \mathrm{~kg} \cdot \mathrm{ha}^{-1}$.

GUI00: Guissona 1999/2000. Barley density: $200 \mathrm{~kg} \cdot \mathrm{ha}^{-1}$.

due to the higher weed densities and better weed establishment conditions (42 vs. $12 \mathrm{~mm}$ of rainfall in the first two months after planting) in this season. Similar results were observed in
Table II. Estimates of parameters for the hyperbolic regressions (eqn 1) of weed biomass $\left(\mathrm{g} \cdot \mathrm{m}^{-2}\right)$ or weed spikes per $\mathrm{m}^{2}$ against weed density $\left(\mathrm{pl} \cdot \mathrm{m}^{-2}\right)$, together with the expected weed biomass or spike reduction at infinite weed density. Standard errors of estimates in parentheses.

\begin{tabular}{lcccc}
\hline Experiment & $i$ & $a$ & Adj R & $\begin{array}{c}\text { Estimated } \\
\text { reductions (\%) }\end{array}$ \\
\cline { 1 - 4 } Weed biomass & & & & \\
ALG94L & $0.920(0.148)$ & $277(42)$ & 0.92 & - \\
ALG94M & $0.961(0.187)$ & $211(29)$ & 0.89 & 24 \\
ALG94H & $0.501(0.074)$ & $142(21)$ & 0.93 & 49 \\
ALG95L & $1.851(0.854)$ & $489(107)$ & 0.76 & -- \\
ALG95M & $1.099(0.312)$ & $346(48)$ & 0.92 & 29 \\
ARG95L & $2.004(0.483)$ & $1317(173)$ & 0.88 & - \\
ARG95M & $1.608(0.291)$ & $1248(151)$ & 0.92 & 5 \\
WH96L & $4.217(2.223)$ & $369(85)$ & 0.72 & - \\
WH96M & $1.909(0.830)$ & $298(93)$ & 0.68 & 19 \\
WH96H & $0.817(0.369)$ & $143(52)$ & 0.78 & 61 \\
GUI00 & $0.207(0.034)$ & $486(88)$ & 0.75 & - \\
Weed spikes & & & & \\
ALG94L & $5.55(0.39)$ & $2114(161)$ & 0.98 & - \\
ALG94M & $6.01(0.46)$ & $1618(95)$ & 0.98 & 24 \\
ALG94H & $4.28(0.62)$ & $1235(183)$ & 0.93 & 42 \\
WH96L & $3.20(0.89)$ & $859(222)$ & 0.87 & - \\
WH96M & $2.70(0.48)$ & $539(83)$ & 0.93 & 37 \\
WH96H & $4.09(2.43)$ & $129(18)$ & 0.82 & 85 \\
\hline
\end{tabular}

GUI00, with $94 \mathrm{~mm}$ of rainfall at the beginning of the season. The maximum L. rigidum biomass estimated in WH96 ranged between 143 and $369 \mathrm{~g} \cdot \mathrm{m}^{-2}$, being similar to that recorded in ALG94. Although weed densities present in WH96 were lower than those in ALG94, the better weed establishment conditions (148 vs. $12 \mathrm{~mm}$ of rainfall in the first two months after planting) and the lower crop densities may explain this similar growth. The largest weed biomass values (1248 to $1317 \mathrm{~g} \cdot \mathrm{m}^{-2}$ ) were those estimated for ARG95. This site was characterised by very high weed densities $\left(>2100\right.$ plants $\left.\cdot \mathrm{m}^{-2}\right)$, favourable weed establishment conditions ( $73 \mathrm{~mm}$ of rainfall in the first two months after planting) and relatively low barley densities.

The $i$ parameter ranged from 0.207 in GUI00 to 4.2 in WH96L, with most of the values close to 1 (Tab. II), but they did not differ significantly within experiments. As expected, the lowest $i$ values were always found in the highest crop densities, supporting the concept that high crop stands tend to reduce the aggressiveness of the weed.

\subsection{Effect of barley and weed densities on the spike density of $L$. rigidum}

The response curves for ALG94 and WH96 show clear hyperbolic relationships between weed spike density per $\mathrm{m}^{2}$ and weed density for each crop density, with $\mathrm{R}^{2}$ being 0.82 or higher (Tab. II and Fig. 2). The maximum density of spikes estimated by the $a$ parameter of the model declined significantly with increasing crop density, from 2114 to 1235 (42\% reduction) in Alguaire and from 859 to 129 (85\% reduction) in Wongan Hills. 

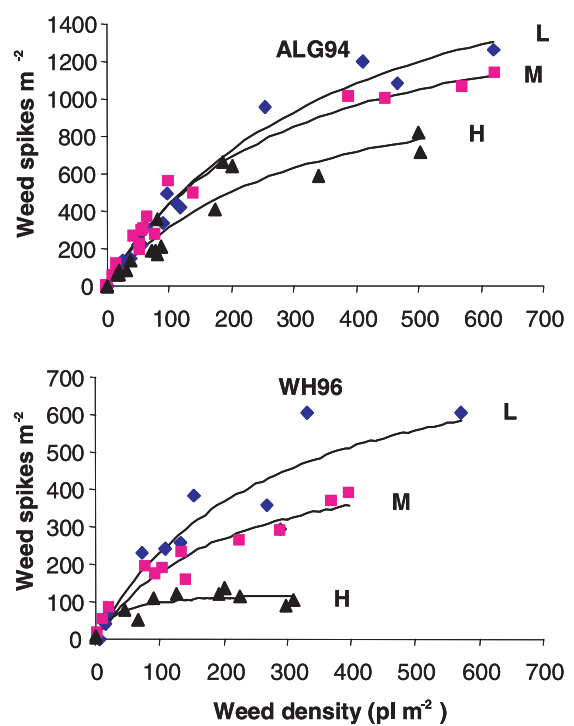

Figure 2. Relationships between the number of spikes $\left(\mathrm{u} \cdot \mathrm{m}^{-2}\right)$ and the density (plants $\cdot \mathrm{m}^{-2}$ ) of $L$. rigidum at the different barley densities. Response curves are those from the parameters given in Table II.

ALG94: Alguaire 1993/94. Barley densities: L $75 \mathrm{~kg} \cdot \mathrm{ha}^{-1}$; M $150 \mathrm{~kg} \cdot \mathrm{ha}^{-1} ; \mathrm{H} 300 \mathrm{~kg} \cdot \mathrm{ha}^{-1}$.

WH96: Wongan Hills 1995. Barley densities: L $25 \mathrm{~kg} \cdot \mathrm{ha}^{-1}$; $\mathrm{M} 50 \mathrm{~kg} \cdot \mathrm{ha}^{-1} ; \mathrm{H} 200 \mathrm{~kg} \cdot \mathrm{ha}^{-1}$.

\subsection{Effect of $L$. rigidum density on barley yield}

Hyperbolic responses were observed in all the experiments except in ALG94 (Fig. 3). Particularly in ALG95 and GUI00, the experimental data presented high variability and, consequently, the parameters of the fitted models showed high standard errors (Tab. III). Due to this variability no different yield losses were observed between the barley sowing densities. In ALG94 L. rigidum density did not affect barley yield, as no significant yield differences were observed with increasing weed density. The estimated yield losses between the weed-free and the highest weed density plot for each experiment were $0 \%$ in ALG94, 36\% in ALG95, 85\% in ARG95, 66\% in WH96 and 44\% in GUI00. Between-site variation in weed competitiveness was evident, as illustrated by the larger yield losses in ARG95 and WH96 as compared with the other sites. Apart from the differences in agronomic management between the sites, this between-site variation could be related to rainfall. There was a significant relationship $(P<0.01)$ between rainfall recorded during the first two months of the growing season and $Y_{w f}\left(\mathrm{r}^{2}=0.76\right)$ and $a\left(\mathrm{r}^{2}=0.78\right)$. Both parameters also showed a significant relationship $(P<0.05)$ with the total rainfall throughout the growing season.

\subsection{Effect of $L$. rigidum density on barley yield components}

The components of yield which showed significant response to $L$. rigidum density are presented in Figure 4 . The density of ears was the component which was affected by
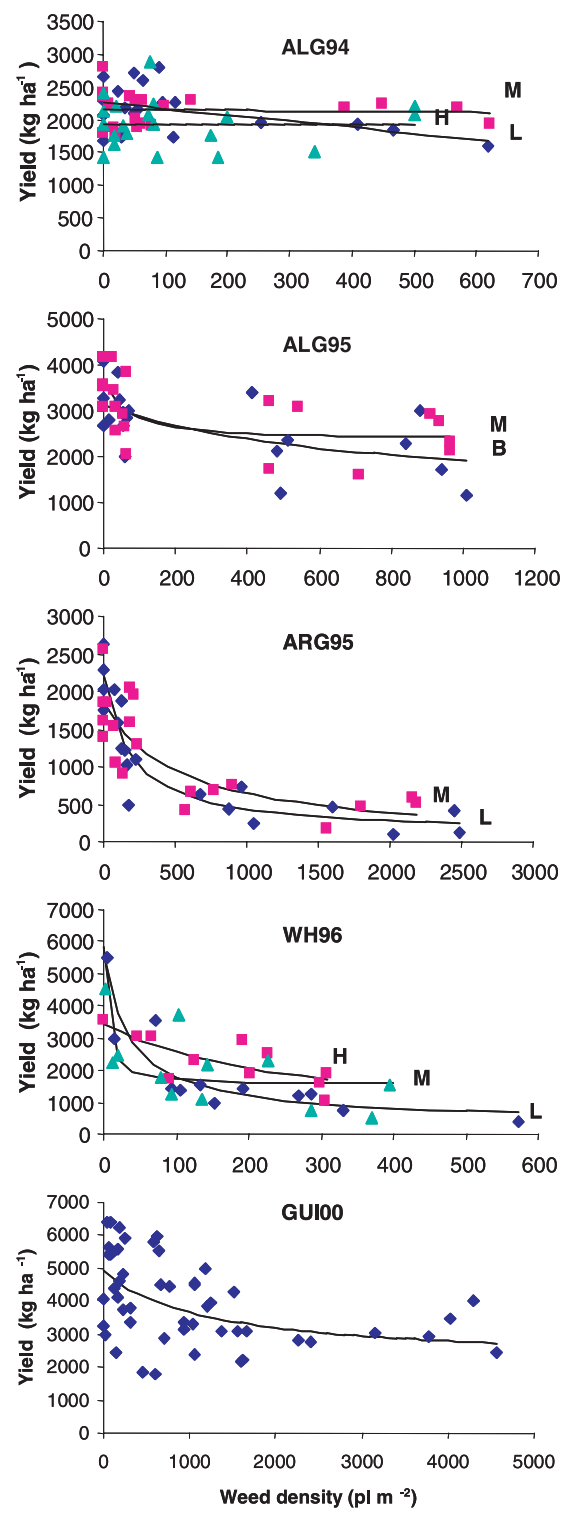

Figure 3. Relationships between the barley yield $\left(\mathrm{kg} \cdot \mathrm{ha}^{-1}\right)$ and the $L$. rigidum density $\left(\mathrm{pl} \cdot \mathrm{m}^{-2}\right)$ at the different barley densities. Response curves are those from the parameters given in Table III.

ALG94: Alguaire 1993/94. Barley densities: L $75 \mathrm{~kg} \cdot \mathrm{ha}^{-1}$; $\mathrm{M} 150 \mathrm{~kg} \cdot \mathrm{ha}^{-1} ; \mathrm{H} 300 \mathrm{~kg} \cdot \mathrm{ha}^{-1}$.

ALG95: Alguaire 1994/95. Barley densities: L $75 \mathrm{~kg} \cdot \mathrm{ha}^{-1}$; M $150 \mathrm{~kg} \cdot \mathrm{ha}^{-1}$.

ARG95: Arganda 1994/95. Barley densities: L $60 \mathrm{~kg} \cdot \mathrm{ha}^{-1}$; M $120 \mathrm{~kg} \cdot \mathrm{ha}^{-1}$.

WH96: Wongan Hills 1995. Barley densities: L $25 \mathrm{~kg} \cdot \mathrm{ha}^{-1}$; M $50 \mathrm{~kg} \cdot \mathrm{ha}^{-1} ; \mathrm{H} 200 \mathrm{~kg} \cdot \mathrm{ha}^{-1}$.

GUI00: Guissona 1999/2000. Barley density: $200 \mathrm{~kg} \cdot \mathrm{ha}^{-1}$.

competition in most of the sites (ALG95, ARG95 and WH96). Furthermore, this component had the highest losses due to L. rigidum competition, with estimated reductions of $30 \%$ in ALG95, 79\% in ARG95 and 60\% in WH96 between the weedfree and the highest weed density. The number of grains per ear was the only component affected in GUI00, while all three 
Table III. Estimates of parameters for the hyperbolic regressions (eqn 2) of yield $\left(\mathrm{kg} \cdot \mathrm{ha}^{-1}\right)$ against weed density $\left(\mathrm{pl} \cdot \mathrm{m}^{-2}\right)$. Standard errors in parentheses.

\begin{tabular}{lcccc}
\hline Experiment & $Y w f\left(\mathrm{~g} \cdot \mathrm{m}^{-2}\right)$ & $i$ & $a$ & Adj. $\mathrm{R}^{2}$ \\
\hline ALG95L & $3114(246)$ & $0.00089(0.00136)$ & $0.68(0.95)$ & 0.37 \\
ALG95M & $3628(299)$ & $0.0060(0.0064)$ & $0.35(0.09)$ & 0.39 \\
ARG95L & $2212(154)$ & $0.0051(0.0016)$ & $0.95(0.08)$ & 0.86 \\
ARG95M & $1842(174)$ & $0.0019(0.0011)$ & $0.99(0.26)$ & 0.67 \\
WH96L & $5610(1065)$ & $0.025(0.018)$ & $0.93(0.10)$ & 0.82 \\
WH96M & $5854(3103)$ & $0.165(0.325)$ & $0.74(0.12)$ & 0.52 \\
WH96H & $3466(518)$ & $0.0036(0.0037)$ & $0.94(0.84)$ & 0.58 \\
GUI00 & $4911(408)$ & $0.00046(0.00039)$ & $0.56(0.23)$ & 0.25 \\
\hline
\end{tabular}

yield components were affected in WH96. The responses of these components to weed density varied, resulting in either a hyperbolic or linear relationship (Tab. IV). No significant differences due to barley sowing rates were observed $(P<0.01)$.

\section{DISCUSSION}

Increases in crop density resulted in a significant reduction in both weed biomass and density of spikes in all the sites, as expected. A significant linear relationship $\left(r^{2}=0.73, P<0.01\right)$ was found between crop density increase and weed biomass suppression when considering all the experiments (Fig. 5). An increase of $50 \%$ in the seeding rate of any cultivar reduced the biomass of the weed by $15 \%$, while if the seeding rate was doubled the weed biomass suppression was $29 \%$. In order to check the consistency of this relationship, further studies should be carried out with more cultivars, sites and seasons. It is anticipated that this relationship would be very useful for an integrated weed management of this weed because it would allow the assessment of how much of an increase in crop density is required to give a particular level of weed biomass suppression in any situation.

The overall response of barley yield to weed density varied considerably between sites and years. The estimated yield losses between the weed-free plots and the highest weed density plots (all crop densities pooled) ranged from 0\% in ALG94 to $85 \%$ in ARG95. Site and seasonal differences in environmental conditions can lead to considerable variation in the competitive ability of L. rigidum and, consequently, the extent and magnitude of yield loss. Poole and Gill [23] have reviewed yield losses due to weeds in experiments throughout Australia and noted that for some species yields were remarkably consistent with respect to weed density, whereas for $L$. rigidum there was far more variability. It was hypothesised that these patterns could be a result of differential rooting of species in comparison with cereals, which influences the ability of species to extract water and/or tolerate water stress. Consequently, it might be expected that if water availability varies from one year to the next, root growth and competitiveness of L. rigidum will also vary. In our experiments, the lowest competition was observed in ALG94, which had a severe drought during the growing season, while the highest competition was observed in AR95 and WH96, which were those sites with the most uniform rainfall distribution throughout the growing season. Gill and Poole [11] found a significant correlation between the
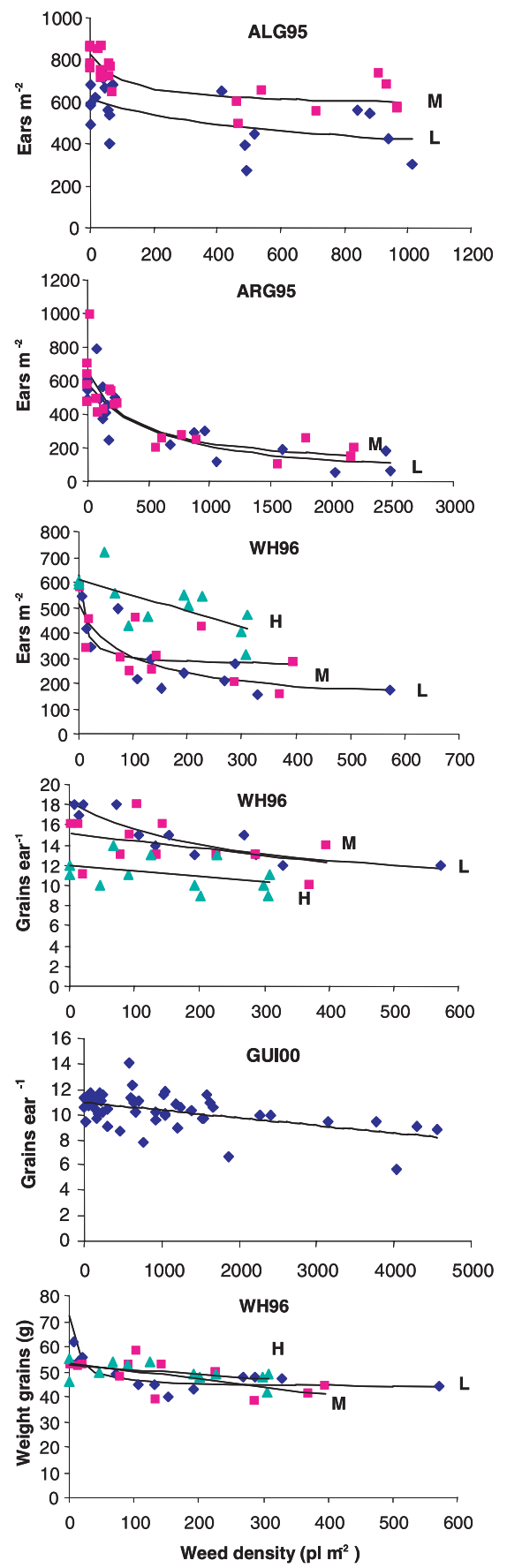

Figure 4. Significant relationships between the barley yield components and the L. rigidum density $\left(\mathrm{pl} \cdot \mathrm{m}^{-2}\right)$ at the different barley densities. Response lines are those from the parameters given in Table IV.

ALG95: Alguaire 1994/95. Barley densities: L $75 \mathrm{~kg} \cdot \mathrm{ha}^{-1}$; M $150 \mathrm{~kg} \cdot \mathrm{ha}^{-1}$.

WH96: Wongan Hills 1995. Barley densities: L $25 \mathrm{~kg} \cdot \mathrm{ha}^{-1}$; M $50 \mathrm{~kg} \cdot \mathrm{ha}^{-1} ; \mathrm{H} 200 \mathrm{~kg} \cdot \mathrm{ha}^{-1}$.

ARG95: Arganda 1994/95. Barley densities: L $60 \mathrm{~kg} \cdot \mathrm{ha}^{-1}$; M $120 \mathrm{~kg} \cdot \mathrm{ha}^{-1}$.

GUI00: Guissona 1999/2000. Barley density: $200 \mathrm{~kg} \cdot \mathrm{ha}^{-1}$. 
Table IV. Estimates of parameters for the linear $(y=a+b x)$ or hyperbolic regressions (eqn 2) of yield components against weed density $\left(\mathrm{pl} \cdot \mathrm{m}^{-2}\right)$. Standard errors in parentheses.

\begin{tabular}{|c|c|c|c|c|c|c|}
\hline \multirow[b]{2}{*}{ Experiment } & \multicolumn{2}{|c|}{ Linear model } & \multicolumn{3}{|c|}{ Hyperbolic model } & \multirow[b]{2}{*}{ Adj. $R^{2}$} \\
\hline & $a$ & $b$ & $Y w f$ & $\bar{i}$ & $a$ & \\
\hline \multicolumn{7}{|l|}{ Ears $\cdot m^{-2}$} \\
\hline ALG95L & & & $615(43)$ & $0.00082(0.00136)$ & $0.51(0.64)$ & 0.34 \\
\hline ALG95M & & & 827 (34) & $0.0029(0.0022)$ & $0.30(0.05)$ & 0.64 \\
\hline ARG95L & & & $583(48)$ & $0.0017(0.0009)$ & $1.01(0.22)$ & 0.76 \\
\hline ARG95M & & & $651(54)$ & $0.0023(0.0012)$ & $0.89(0.17)$ & 0.72 \\
\hline WH96L & & & $513(82)$ & $0.0089(0.0084)$ & $0.76(0.20)$ & 0.68 \\
\hline WH96M & & & $632(178)$ & $0.0601(0.0971)$ & $0.57(0.12)$ & 0.50 \\
\hline WH96H & $613(40)$ & $-0.64(0.21)$ & & & & 0.43 \\
\hline \multicolumn{7}{|l|}{${\text { Grains } \cdot \text { ear }^{-1}}^{-1}$} \\
\hline GUI00 & $10.97(0.23)$ & $-0.0006(0.0001)$ & & & & 0.24 \\
\hline WH96L & & & $18.4(0.8)$ & $0.0022(0.0011)$ & $0.51(0.16)$ & 0.83 \\
\hline WH96M & $15.11(0.99)$ & $-0.007(0.005)$ & & & & 0.10 \\
\hline WH96H & $11.92(0.78)$ & $-0.005(0.004)$ & & & & 0.07 \\
\hline \multicolumn{7}{|c|}{ Weight } \\
\hline \multicolumn{7}{|c|}{1000 grains $(\mathrm{g})$} \\
\hline WH96L & & & $72(13)$ & $0.036(0.045)$ & $0.39(0.10)$ & 0.81 \\
\hline WH96M & $53.41(2.31)$ & $-0.032(0.011)$ & & & & 0.38 \\
\hline WH96H & $52.54(1.63)$ & $-0.017(0.0085)$ & & & & 0.24 \\
\hline
\end{tabular}

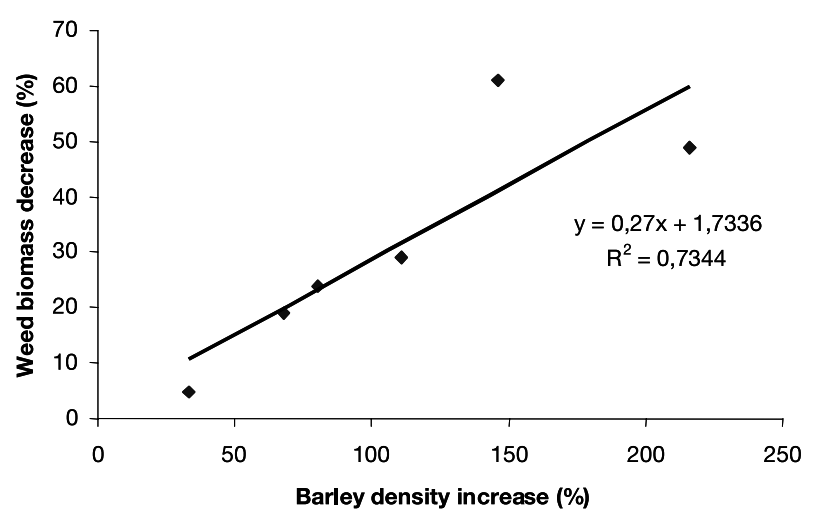

Fig. 5. Effect of the increase in the density of barley with respect to the lowest barley density on the biomass of $L$. rigidum in the experiments.

competitive ability of $L$. rigidum and rainfall at the beginning of the growing season. Their results showed that a dry beginning to the growing season reduced the competitiveness of this species. They hypothesised that drying of the surface layer of soil may exceed the rate of root elongation of $L$. rigidum, resulting in a decrease in the rate of germination, a delay in establishment and therefore reduced competitive ability. In ALG94 only $11 \mathrm{~mm}$ of rainfall were recorded during the first three months after sowing. Site conditions in this experiment were also characterised by a marked shortage of precipitation during most of the remaining season, with plants showing clear water stress symptoms during the winter and early spring. Under these types of conditions $L$. rigidum caused practically no yield losses. In ALG95, although overall rainfall was the lowest collected in all the experiments, most of it $(42 \mathrm{~mm})$ occurred at the beginning of the season, allowing good establishment of the plants. These conditions promoted moderate yield loss levels.
The strongest effects of weed competition were those observed in the other three experiments, which experienced relatively wet beginnings of the growing seasons (148 mm in WH96, $73 \mathrm{~mm}$ in ARG95 and $94 \mathrm{~mm}$ in GUI00). This positive relationship between rainfall recorded in the first two months of growth with the expected yield at saturation density (parameter $a$ of the model) indicates that L. rigidum was more affected by the shortage of rainfall than barley, probably related to the fact that its roots are mostly near the soil surface. Mediterranean environments are characterised by a high year-toyear and seasonal variability of rainfall, with frequent periods of drought during the growing season that may seriously affect the growth and development of cultivated plants [1]. Consequently, the inter- and intra-specific competitive relationships between plants may also vary greatly, making it particularly difficult to develop accurate predictive models of yield losses without considering seasonal factors such as rainfall.

The competitive ability of $L$. rigidum may be substantially greater in commercial fields than that observed in our experiments. A single hydration-dehydration cycle caused by summer rainfalls approximately doubled the speed of germination of L. rigidum by shortening the lag phase of germination [19], and the period of the weed emergence relative to the crop can vary the competitiveness of the weed; if the weed emerges earlier than or at the same time as the crop then it becomes more competitive [27]. The L. rigidum seeds used in our experiments had been stored in a dry environment since the end of the previous season, so no hydration - dehydration cycles occurred that could speed up germination. Weed emergence in ALG95 and in ARG95 started six and three days after crop emergence, respectively, but in ALG94 weeds emerged two weeks later than barley. In this situation, the seedlings would have been less competitive than usual. In commercial fields, a relatively large proportion of $L$. rigidum seedlings are established well in advance of crop emergence, being able to survive preplanting 
tillage operations. These plants are expected to be much more competitive than those established in our experiments.

In most of the experiments, a considerable part of the effect of the competition on the yield of barley was due to a reduction in the number of grain-bearing ears per plant. The number of ears are directly related to the number of tillers. As tillering takes place early in the growing season, the strongest competition may have taken place in the early stages of the development of the crop, mainly where there was a good water supply at this time, as in ARG95 and WH96. The earlier the onset of stress within a growing season, the greater the effect on yield [1]. To a lesser extent, the number of grains per ear (GUI00 and WH96) also contributed to the yield losses recorded. The ability of weeds to affect crop grain number and tiller number is well established $[5,20]$. Thousand grain weight was the yield component least affected by weed competition. The response of the components of yield to the effect of the weed seems to be quite consistent whatever the crop density.

A common observation in all these experiments was that increasing the seeding rate of the crop did not significantly reduce yield losses in barley. However, the increase in crop density had the benefit of suppressing weed biomass. Crop yield losses were very variable and related to water availability at the beginning of the season. These results support the view that the key to gaining better predictions of yield loss is a thorough understanding of the impact of environmental factors (particularly soil moisture at the beginning of the season) on the competitive abilities of both the crop and the weed.

Acknowledgments: This study was supported by the Spanish project CYCIT number AGF 93-0752-C04. The Direcció General de Recerca of the Generalitat de Catalunya funded the experiment carried out in Australia by the first author. We thank the staff of the Weed Science section of Agriculture of Western Australia for their technical assistance.

\section{REFERENCES}

[1] Apinall D., Nichols P., May L.H., The effects of soil moisture stress on the growth of barley. I. Vegetative development and grain yield, Aust. J. Agric. Res. 15 (1964) 729-745.

[2] Bravin F., Zanin G., Preston C., Diclofop-methyl resistance in populations of Lolium spp. from central Italy, Weed Res. 41 (2001) 49-58.

[3] Cousens R.D., A simple model relating yield loss to weed density, Ann. Appl. Biol. 107 (1985) 239-252.

[4] Cousens R.D., Comparative growth of wheat, barley and annual ryegrass (Lolium rigidum) in monoculture and mixture, Aust. J. Agric. Res. 47 (1996) 449-464.

[5] Cousens R.D., Firbank L.G., Mortimer A.M., Smith G.R., Variability in the relationship between crop yield and weed density for winter wheat and Bromus sterilis, J. Appl. Ecol. 25 (1988) 1033-1044.

[6] Cousens R.D., Mokhtari S., Seasonal and site variability in the tolerance of wheat cultivars to interference from Lolium rigidum, Weed Res. 38 (1998) 301-307.

[7] Davidson R.M., Management of herbicide resistant annual ryegrass, Lolium rigidum, in crops and pastures, Proc. 9th Aust. Weeds Conf., Adelaide (1990), pp. 230-233.

[8] Dhima K.V., Eleftherohorinos I.G., Influence of nitrogen on competition between winter cereals and sterile oat, Weed Sci. 49 (2001) 77-82.
[9] Garcia Baudin J.M., Importancia de los vallicos en los cereales de invierno españoles, Bol. - Serv. Def. contra Plagas Insp. Fitopatol. 9 (1982) 179-188.

[10] Gill G.S., Development of herbicide resistance in annual ryegrass populations (Lolium rigidum Gaud.) in the cropping belt of Western Australia, Aust. J. Exp. Agric. 35 (1995) 67-72.

[11] Gill G.S., Poole M.L., Variation in competitive ability of annual ryegrass in wheat crops of Western Australia, Aust. Weeds Res. Newsl. 35 (1986) 15-19.

[12] Gill G.S., Cousens R.D., Allan M.R., Germination, growth, and development of herbicide resistant and susceptible populations of rigid ryegrass (Lolium rigidum), Weed Sci. 44 (1996) 252-256.

[13] Goldberg D.E., Components of resource competition in plant communities, in: Grace J.B., Tilman D. (Eds.), Perspectives in Plant Competition, San Diego, Academic Press, 1990, pp. 27-49.

[14] Gramshaw D., Stern W.R., Survival of annual ryegrass (Lolium rigidum Gaud.) in a Mediterranean type environment. II. Effects of short term burial on persistence of viable seed, Aust. J. Agric. Res. 28 (1977) 93-101.

[15] Heap J., Knight R., A population of ryegrass tolerant to the herbicide diclofop-methyl, J. Aust. Inst. Agric. Sci. 48 (1982) 156-157.

[16] Lemerle D., Verbeeck B., Coombes N.E., Losses in grain yield of winter crops from Lolium rigidum (Gaud.) depend on crop species, cultivar and season, Weed Res. 35 (1995) 503-509.

[17] Lemerle D., Verbeeck B., Cousens R.D., Coombes N.E., The potential for selecting wheat varieties strong competitive against weeds, Weed Res. 36 (1996) 505-513.

[18] Lemerle D., Verbeeck B., Orchard B., Ranking the ability of wheat varieties to compete with Lolium rigidum, Weed Res. 41 (2001) 197-209.

[19] Lush W.M., Groves R.H., Germination, emergence and surface establishment of wheat and ryegrass in response to natural and artificial hydration-dehydration cycles, Aust. J. Agric. Res. 32 (1981) 731-739.

[20] Medd R.W., Auld B.A., Kemp D.R., Murison R.D., The influence of wheat density and spatial arrangement on annual ryegrass, Lolium rigidum Gaudin, competition, Aust. J. Agric. Res. 36 (1985) 361-371.

[21] Nietschke B., Llewellyn R., Matthews J.M., Powles S.B., Reeves T.G., A survey of herbicide resistant Lolium and Avena species in South Australia, Proc. 8th Aust. Agron. Conf., Toowoomba (1996), pp. 691-692.

[22] Poole M.L., Competition between crops and ryegrass, Proc. West. Aust. Weeds Conf., Muresk (1979), pp. 95-97.

[23] Poole M.L., Gill G.S., The use of weed density - crop yield relationships for predicting yield losses in the field, Proc. Br. Crop Prot. Conf. - Weeds, Brighton (1987) 945-954.

[24] Preston C., Tardif F.J., Powles S.B., Multiple mechanisms endow multiple herbicide resistance in Lolium rigidum, in: Brown T.M. (Ed.), Molecular Genetics and Ecology of Pesticide Resistance, American Chemical Society Symposium Series 645, Washington DC, 1996.

[25] Recasens J., Riba F., Izquierdo J., Forn R., Taberner A., Gramíneas infestantes de los cereales de invierno de Cataluña, ITEA 2 (1996) 116-130.

[26] Reeves T.G., Broke H.D., The effect of genotype and phenotype on the competition between wheat and annual ryegrass (Lolium rigidum Gaud.), Proc. Sixth Conf. Asian Pac. Weed Sci. Soc., Jakarta, Indonesia (1977), pp. 167-172.

[27] Rerkasem K., Stern W.R., Goodchild N.A., Associated growth of wheat and annual ryegrass. I. Effect of varying total density and proportion in mixtures of wheat and annual ryegrass, Aust. J. Agric. Res. 31 (1980) 649-658.

[28] Saavedra M., Cuevas J., Mesa-Garcia J., Garcia Torres L., Gras weeds in winter cereals in southern Spain, Crop Prot. 8 (1989) 181187.

[29] Skorda E.A., Epthimiadis P., Effect of wheat seed rate on Lolium rigidum competition, Proc. Br. Crop Prot. Conf. - Weeds, Brighton (1989) 399-404. 